doi: 10.5455/2319-2003.ijbcp001512

Review Article

\title{
Cannabinoids and their medicinal potential
}

\author{
Deepika Tikoo*, Geeta Sharma, Meenakshi Gupta
}

Department of Pharmacology, Sri Guru Ram Das Institute of Medical sciences and Research, Vallah, Amritsar-143001, Punjab, India

Received: 30 August 2012

Revised: 20 September 2012

Accepted: 29 September 2012

*Correspondence to:

Dr. Deepika Tikoo,

E-mail: dtikoo@gmail.com

\begin{abstract}
Cannabis sativa $L$ preparations have been used therapeutically since many years. Inspite of their medicinal value, the danger of its abusive potential led to the ban on its use in clinical practice in many countries. The recent research and in depth knowledge about the cannabinoid system which throw a light on their disease management potential has paved way for the cannabinoids to become a new therapeutic focus of attention. Cannabinoids are a group of compounds that mediate their effects through cannabinoid receptors which include $\mathrm{CB}_{1}$, predominantly expressed in the brain and $\mathrm{CB}_{2}$ which is primarily found in the cells of the immune system. Despite the addictive properties of cannabis, the therapeutic value of cannabinoids is too high to be put aside. Numerous diseases such as anorexia, pain, inflammation, obesity, cardiovascular disorders, neurodegenerative diseases, cancer, gastrointestinal diseases, hepatic disorders, skin related diseases, respiratory disorders like asthma and eye diseases like glaucoma have suggested cannabinoid agonists/ antagonists/ cannabinoids related compounds as potential treatment options. Developments of new specific ligands for the cannabinoid receptors are now underway and it needs to be seen, if in future, they can prove to be a boon for the medical world. The paper reviews the current understanding of the cannabinoid receptors, their ligands and their possible role in various diseases supported by preclinical and clinical studies.
\end{abstract}

Keywords: Cannabinoids, cannabinoid receptors, clinical practice

\section{INTRODUCTION}

Cannabinoids are the active compounds from the plant Cannabis sativa and the first major psychoactive component of cannabis discovered was $\Delta^{9}$ tetrahydrocannabinol (THC) in 1964. Further research in this field eventually led to the discovery of endogenous cannabinoids (endocannabinoids) which were the naturally occurring substances within the body and they mimicked the action of THC. ${ }^{1}$ The first successful endocannabinoid ligand discovered in the process was arachidonylethanolamide named as Anandamide, which in Sanskrit means 'bliss'(a-nanda) + amide. Later, a second endocannabinoid, 2-arachidonoyl glycerol (2-AG) was identified. Other less well established endocannabinoid candidates are virhodamine, nolandin and $N$-Arachidonoyl dopamine. ${ }^{2}$

The serendipitous identification of the heptahelical Gprotein-coupled receptors $\mathrm{CB}_{1}$ and $\mathrm{CB}_{2}$ in 1990 s fuelled further interest in the cannabinoid galaxy. $\mathrm{CB}_{1}$ receptors, which activate G-proteins mainly of the Pertussis toxin (PTX)-sensitive Gi/Go family are expressed in both central nervous system (mainly) and in the periphery. In the central nervous system, they are present in the hippocampus, cerebellum, hypothalamus, substantia nigra, mesolimbic dopamine pathways and in association areas of cerebral cortex. ${ }^{3,4}$ Activation of $\mathrm{CB}_{1}$ receptors, which are present pre-synaptically leads to inhibition of adenylate cyclase and calcium channels while causing activation of potassium channels which results in inhibition of synaptic transmission. In the periphery, $\mathrm{CB}_{1}$ receptors are present in endothelial cells and adipocytes where they promote lipogenesis and regulate arterial tone and vasorelaxation. ${ }^{2,5}$

$\mathrm{CB}_{2}$ receptors are mainly expressed in the immune system (spleen, tonsils, thymus, circulating lymphocytes, monocytes and mast cells of the tissues) with much lower distribution in the CNS. ${ }^{6}$ Activation of cannabinoid receptors can produce other physiological effects like antinociception, hypothermia, sedation, hypotension, inhibition of intestinal motility and motor depression. ${ }^{2}$ 
Cannabinol, the precursor of THC and cannabidiol, a breakdown product of THC which is devoid of psychoactive effects, are the most abundant plant cannabinoids obtained from the plant Cannabis sativa. $\Delta^{9}$ tetrahydrocannabinol, which is the active principle when given to humans results in a lot of central and peripheral effects. The behavioral effects include physical relaxation, feeling of well being, mild euphoria, impaired motor coordination, stimulation of appetite, antiemetic action and analgesia. Chronic use results in decreased attention, verbal learning and memory and increases the chances of developing psychiatric disorders. ${ }^{7}$ The peripheral effects include tachycardia, vasodilatation, decreased intraocular pressure and bronchodilatation. ${ }^{2}$

Endogenous cannabinoids, anandamide and 2-AG are synthesized and released when 'demanded' and not stored in the 'resting' cells. They are synthesized and released in response to various physiological and pathological stimuli like neuronal depolarization and bacterial lipopolysacchrides. ${ }^{4}$ Anandamide is synthesized from Nacyl-phosphatidylethanolamines (NAPEs) via enzymatic conversion by transacylase and phospholipase D. ${ }^{4}$ It is an agonist at $\mathrm{CB}_{1}$ receptors mainly with very low affinity for $\mathrm{CB}_{2}$ receptors. ${ }^{8,9}$ Endocannabinoids have also been seen to act on certainG-protein coupled receptors (GPCRs) like GPR55 and ion channels like vanilloid receptor-type1 (TRPV1 receptors). ${ }^{7}$

Anandamide from the extracellular space is rapidly taken up by neurons and other cells by selective, saturable, temperature dependant and $\mathrm{Na}^{+}$independant facilitated transport mechanisms called as anandamide membrane transporters (AMT). It then gets metabolized by fatty acid amide hydrolase (FAAH) to arachidonic acid and ethanolamine. ${ }^{4}$

2-arachidonoyl glycerol is synthesized by hydrolysis from phosphitidyl inositol by action of the enzymes phospholipase $\mathrm{G}$ and diacylglycerol lipases (DAGL- $\alpha$ and DAGL- $\beta$. It binds to both $\mathrm{CB}$ receptors but somewhat has a higher affinity for $\mathrm{CB}_{2}$ receptors. ${ }^{1}$ Although $2-\mathrm{AG}$ is also hydrolyzed by FAAH to arachidonic acid and glycerol in vitro but in vivo it is hydrolyzed by a monoacylglyceride lipase (MGL) which is co-expressed with $\mathrm{CB}_{1}$ receptors in hippocampus. ${ }^{10-13}$

The knowledge about cannabinoid system due to the availability of many preclinical and clinical studies during the past few years has paved way for them to become a new therapeutic focus of attention. Novel ligands for the $\mathrm{CB}_{1}$ and $\mathrm{CB}_{2}$ receptors are being synthesized and developed and their possible role as a future treatment modality in various diseases has been discussed below.

For this review article, resources which were relevant to the topic were searched in the months of August and September from online papers (pubmed) using the key words cannabinoids, cannabinoid receptors, rimonabant, endocannabinoids, therapeutic potential, novel therapeutic targets. Apart from text selection from text book (Rang and Dale's Pharmacology $6^{\text {th }}$ edition), more than 100 articles from pubmed were retrieved (including abstracts) and 94 out of them were used for preparation of the review which have been mentioned in the reference list. The articles were studied and the ones (especially the full length available articles) in which the information regarding the outline of endocannabinoid system including the cannabinoid receptors, novel therapeutic potential of cannabinoids in various diseases with supporting evidence was presented and discussed in details, were considered. All the data gathered was then used to draft a review article about cannabinoids, highlighting their therapeutic implications, by the authors, with an aim to cover all the important aspects.

\section{THERAPEUTIC POTENTIAL OF CANNABINOIDS}

\section{Appetite, Emesis and Obesity}

The endocannabinoid system via $\mathrm{CB}_{1}$ receptors regulates central appetite control, peripheral metabolism and body weight management. Anorexia remains a grave problem in patients suffering from cancer or AIDS. In Unites States (US) and many European countries, a synthetic delta-9-THC preparation (dronabinol, marinol) and its synthetic analog (nabilone, Cesamet), which are primarily approved for treatment of nausea and vomiting in cancer and HIV infected patients, caused a consistent improvement in appetite along with improvement in mood in this patient population. Dronabinol was efficacious and safe in HIV wasting syndrome and advanced cancer and it showed greater efficacy than conventional antiemetics like chlorpromazine and similar drugs in chemotherapy induced emesis and patients preferred them. ${ }^{14,15}$ But their side effects like dizziness, dysphoria, hallucinations may limit their widespread use while sedation and euphoria seemed to be preferred by the patients. ${ }^{16}$ Therefore it becomes important to identify selective/ specific group of patients who will benefit from the antiemetic effect of cannabinoids and also have less neuropsychiatric adverse effects.

The other side of the coin is obesity, and cannabis has been known to increase appetite and food consumption. One of the first generation $\mathrm{CB}_{1}$ receptor blocker, rimonabant was seen to cause short term reduction in food intake by its central action. Various studies investigating the effect of rimonabant in obese patients with hyperlipidemia demonstrated that rimonabant caused a significant decrease in hunger, body weight along with improvement in insulin resistance, increase in HDL cholesterol levels and decrease in triglyceride levels as compared to placebo group. ${ }^{14,15}$ But adverse effects like depression and suicidal ideations have halted its usage in many European countries and it did not get the approval of Food and Drug Administration (FDA). This alongside also led to the termination of development of other $\mathrm{CB}_{1}$ receptor blockers like taranabant and otanabant. ${ }^{17,18}$ 
Still the interest in the potential of $\mathrm{CB}_{1}$ antagonists called the peripherally restricted $\mathrm{CB}_{1}$ receptor antagonists is retained and several such compounds are being synthesized and developed. These compounds will attain lower brain concentrations and will be free of the aversive side effects seen with rimonabant. ${ }^{17-19} \mathrm{~A}$ novel peripherally active cannabinoid receptor antagonist, AM6545, which is more selective for $\mathrm{CB}_{1}$ than $\mathrm{CB}_{2}$ was tested in rodents to evaluate its effect on food intake and body weight. This agent showed limited brain permeability and dose dependently reduced food intake and inhibited body weight gain in rodents. ${ }^{17}$ Hence $\mathrm{CB}_{1}$ receptor antagonists designed to have limited brain permeability hold a promising future in weight management.

\section{Neuro-inflammatory and neurodegenerative disorders}

\section{Multiple Sclerosis}

Multiple Sclerosis (MS) is a chronic inflammatory, autoimmune and demyelinating disease of the brain which results in muscle weakness, spasticity, tremors, ataxia, cognitive impairment, difficulty in coordination and balance, loss of bladder control and constipation. Degeneration of myelin sheath is mediated by $\mathrm{T}$ cells and this inflammatory process causes breakdown of blood brain barrier (BBB) which further activates macrophages \& produces cytokines. ${ }^{19}$

Cannabis has been used in the past to relieve muscle cramps/ spasms and pain. ${ }^{20}$ Current knowledge about the endocannabinoid system changes in MS patients has revealed that both $\mathrm{CB}_{1}$ and $\mathrm{CB}_{2}$ expressing cells collect around plaques in human MS oligodendrocytes, along with their precursors and macrophages while perivascular $\mathrm{T}$ cells expressing $\mathrm{CB}_{1}$ receptors have been identified to be present in multiple sclerosis. Microglia and macrophages forming plaques, nearby astrocytes and $\mathrm{T}$ cells express $\mathrm{CB}_{2}$ receptors. ${ }^{21}$ In blood samples of primary progressive $\mathrm{MS}$ patients, an up-regulation of $\mathrm{CB}_{1}$ and $\mathrm{CB}_{2}$ levels has been detected which shows that immune regulation of the endocannabinoid system occurred both in brain as well as periphery. ${ }^{22}$

Various animal and human studies of MS, demonstrating the role of endocannabinoids have been done. In an experimental autoimmune encephalomyelitis (EAE) rat model, parenteral THC demonstrated inhibition of neural inflammation and improved survival. ${ }^{20}$ Dexabinol, a nonpsychoactive synthetic cannabinoid also caused a reduction in the inflammatory response in the brain and spinal cord of EAE rats. Cannabinoids cause immunosuppression by induction of apoptosis via partial activation of $\mathrm{CB}_{2}$ receptors and also decreased production of IL-2, IFN- $\gamma$ and TNF- $\alpha$ production by activated T cells which is a $\mathrm{CB}_{1}$ receptor mediated effect. ${ }^{19}$ Other mechanism by which cannabinoids offer immunoprotective action is by action on astrocytes which during disease progression are activated to release cytokines, chemokines and nitric oxide (NO).
Cannabinoids in various studies have been found to trigger production of IL-6 (which inhibits TNF- $\alpha$ ), inhibit NO production and decrease various other inflammatory products. $^{15,23}$

In another model of MS in mice called as chronic relapsing experimental allergic encephalomyelitis (CREAE) which reproduces many pathological features of MS found in humans, decrease in $\mathrm{CB}_{1}$ receptor density in caudate-putamen, globus pallidus and cerebellum was seen. The cannabinoids improve motor symptoms like spasticity, tremors and ataxia. ${ }^{19,20}$ These mice showed an increase in AEA, 2-AG and palmitoylethanolamide (PEA) levels in areas of nerve damage and selective inhibitors of endocannabinoid transport or hydrolysis also relieved spasticity in EAE. ${ }^{24,25}$ In $\mathrm{CB}_{1}$ deficient mice, substantial neurodegeneration developed on inducing EAE. ${ }^{20}$

In a survey in 112 humans with MS in USA and UK, who took cannabis as self medication, it was seen that cannabis improved spasticity, pain, tremors, depression in majority of the patients. ${ }^{20,26}$ Another large multicentric study conducted in MS patients who received either synthetic THC or a Cannabis or placebo, recorded significant improvements in spasticity, pain and sleep quality of the patients. The 12 month follow up also showed a remarkable decrease in spasticity. ${ }^{20,27}$ In contrast one of the studies reported impairment in both balance and posture after a single dose of smoked cannabis in MS patients and normal subjects. ${ }^{28}$

All these studies have shown mixed results and it remains to be seen whether cannabinoids with targeted drug delivery, optimized for modifying neuroinflammation will be useful in MS treatment. Future large scale trials are needed to establish them as efficacious therapeutic modality in management of multiple sclerosis.

\section{Amyotrophic lateral sclerosis (ALS)}

It is a neurodegenerative disease characterized by progressive loss of cortical motor neurons in the spinal cord, brain stem and motor cortex, leading to muscle wasting, weakness and spasticity, which can progress to

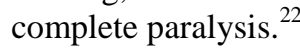

In SOD1G93A mice, a model of ALS, cannabinoids was seen to delay onset of symptoms and prolong survival by non $\mathrm{CB}_{1}$ receptor mechanism. ${ }^{15}$ Genetic ablation of FAAH, the enzyme responsible for metabolizing endocannabinoids, prevented the onset of disease signs in these mice. $\mathrm{CB}_{1}$ receptor induced mechanism did not seem to play a role in this. A safety study of THC done on ALS patients showed beneficial effects in spasticity, insomnia and appetite. ${ }^{22}$ Very few clinical studies evaluating the benefits of cannabinoids are available in ALS patients and there seems to be hope for them as preclinical studies have shown the neuroprotective effect of cannabinoids. 


\section{Parkinson's disease (PD)}

Another chronic and progressive neurodegenerative disease, PD is characterized by degeneration of dopamine containing neurons in substantia nigra which causes bradykinesia, tremor and rigidity in the patients. The progression of neurodegeneration and appearance of major motor symptoms are related to increased endocannabinoids. Various studies have found an increase in the $\mathrm{CB}_{1}$ receptor levels in the striatum of monkeys and humans with parkinsonism. Activation of $\mathrm{CB}_{1}$ receptor signaling reduced the glutamate release from the cortex of striatum (beneficial effect) and enhanced GABA transmission causing inhibition of globus pallidus (non beneficial effect). ${ }^{20,29}$ Therefore use of $\mathrm{CB}_{1}$ antagonists can have pro or antiparkinsonian actions depending upon the target area. $\mathrm{CB}_{1}$ receptor agonists can cause a decrease in the tremors due to overactivity of subthalamic nucleus and improve motor symptoms while $\mathrm{CB}_{1}$ antagonists can be used to alleviate bradykinesia. ${ }^{20}$ Administration of $\mathrm{CB}_{1}$ antagonists in animals showed an improvement in parkinsonian symptoms and levodopa induced dyskinesias. $^{30}$

We have many preclinical studies demonstrating the therapeutic potential of cannabinoids in PD but clinical trials in this area are still limited and in the coming years it is expected that the number of studies examining this potential will increase and provide us with a clear picture of its role in PD management.

\section{Alzheimer's disease (AD)}

The pathogenesis of AD involves loss of cholinergic neurons in hippocampus and frontal cortex which leads to cognitive deficit and loss of short term memory in patients. There occurs formation of extracellular, amyloid plaques consisting of $\beta$ amyloid proteins and intraneuronal neurofibrillary tangles containing hyperphosphorylated microtubule associated tau proteins. There occurs acceleration of the formation of above protein aggregates, neuronal inflammation and hence loss of neurons with disease progression. ${ }^{2}$ THC competitively inhibits acetylcholinesterase and thus prevents acetylcholinesterase induced $\beta$ amyloid protein aggregation. ${ }^{31} \mathrm{CB}_{2}$ receptor stimulation is also involved in suppression of inflammatory mediators like NO, chemokines and cytokines involved in neuronal damage. ${ }^{32}$ Hence if these findings are further confirmed in future, there can be a ray of light for the patients of Alzeimer's disease.

\section{Huntington's disease (HD)}

It is an inherited autosomal dominant disorder resulting in progressive brain degeneration and is associated with choreiform movements, motor disturbance and cognitive deficits. There occurs reduction in the activity of glutamic acid decarboxylase (GAD), an enzyme responsible for synthesis of gamma amino butyric acid (GABA) and this loss of GABA mediated inhibition in the basal ganglia causes hyperactivity of dopaminergic synapses. ${ }^{2}$ Also, there occurs loss of $\mathrm{CB}$ receptors in substantia nigra in
HD patients. A hybrid endocannabinoid and vanilloid compound (arvanil) exhibited antihyperkinetic action in rat $\mathrm{HD}$ model. ${ }^{15}$ Administration of $\mathrm{CB}$ receptor agonist have been shown to have neuroprotective effects by preventing glutamate induced excitotoxicity. A small trial with Nabilone and cannabidiol showed no efficacy in HD patients and increased choreatic movements in them. ${ }^{20}$ Therefore, these results do not support the results of preclinical studies but, very few clinical studies have been done so far and more are needed to establish the usefulness of cannabinoids in HD. Also it is important to evaluate whether cannabinoids are important in early phase of the disease or even in advanced stages.

\section{Psychiatric disorders}

\section{Schizophrenia}

Schizophrenia is a functional disorder characterized by positive symptoms like delusions, illusions, hallucinations, thought disorders, distortion of perception and aggressive behaviour at times. The psychotic episodes are separated by periods with negative symptoms like introvert behaviour, poor socialization, emotional blunting, lack of motivation and attention deficit along with loss of memory. ${ }^{33}$

Hypoglutamatergic and hypodopaminerigic transmission in the prefrontal cortex may be causing negative symptoms while increased dopaminergic transmission in the mesencephalic projections to nucleus accumbens could lead to positive symptoms. ${ }^{20}$ It has been seen that overactivity of the endocannabinoid system may lead to a increased dopaminergic and decreased glutamatergic levels, which may cause some of the symptoms of schizophrenia. $^{20,34}$

Various theories supporting the endocannabinoid hypothesis in schizophrenia have been presented. It has been reported that cannabis has worsened the positive symptoms of schizophrenia in patients even when they were on antipsychotics. ${ }^{34,35}$ Also, the use of large amounts of cannabis and THC are likely to produce psychotic symptoms in normal individuals, including delusions, hallucinations, and impairment of cognitive functions just like schizophrenia. ${ }^{8,36,37}$ Heavy use of cannabis can be an independent risk factor for development of schizophrenia in susceptible patients. ${ }^{38}$ The levels of anandamide are found to be elevated in cerebrospinal fluid or blood taken from patients of schizophrenic and treatment with neuroleptics corrects this endocannabinoid imbalance. ${ }^{39,40}$ Two independent postmortem studies showed an increase of $\mathrm{CB}_{1}$ receptors in subregions of the prefrontal cortex, dorsolateral and anterior cingulate regions in schizophrenia. As it is known that cannabinoids impair cognition, attention, and motivation, it can be postulated that the increase in $\mathrm{CB}_{1}$ receptors in the prefrontal cortex may be involved in schizophrenia especially the negative symptoms. $^{34}$ 
Hence, utilization of $\mathrm{CB}_{1}$ receptor antagonists may be used for treatment of negative symptoms of schizophrenia, but if its other neurological side effects can be prevented is a question of prime importance as such undesirable effects will not be acceptable and can limit its usefulness.

\section{Mood disorders}

Evidences have suggested possible use of cannabinoids in treating mood disorders like generalized anxiety and depression. $\mathrm{CB}_{1}$ receptors are widely distributed in brain areas associated with emotional regulation and stress responsiveness such as prefrontal cortex, hippocampus, amygdala, and hypothalamus, suggesting its role in anxiety-related disorders. ${ }^{41}$

$\mathrm{CB}_{1} \mathrm{R}$ knock-out mice display increased anxiety levels compared to control animals (wild-type) in a variety of behavioral paradigms like the light-dark box, the elevated plus- maze test and the social interaction test. Adult rodents treated with low dose nabilone and THC exerted anxiolytic effects in elevated plus maze model. ${ }^{41,42}$ Similarly, rimonabant, a cannabinoid antagonist produced anxiogenic effects in rats in elevated plus- maze and defensive withdrawal test. In contrast, rimonabant was found to be anxiolytic in mice in another elevated plusmaze study. ${ }^{41}$ But clinical data supports the anxiogenic effect of rimonabant seen in rats because it was withdrawn from the market as an anti obesity drug for causing increased anxiety and depressive mood. ${ }^{41,43}$ Facilitation of anxiolytic endocannabinoid tone by inhibitors of FAAH or anandamide transport also elicited anti anxiety and antidepressants effects in animal studies. $^{14}$

The results suggest that amplification of the endocannabinoid signaling by mechanisms like inhibition of their transporters or FAAH can be an innovative target for treatment of anxiety disorders as this will not be associated with psychoactive adverse effects.

\section{Insomnia}

Insomnia is defined as difficulty in initiation, maintenance, duration or quality of sleep. Earlier studies have shown the effects of marijuana and THC on sleep patterns in humans and animals. A recent study of cannabis extracts in eight healthy volunteers on sleep quality, early morning performance and memory showed that $15 \mathrm{mg}$ of THC was sedative while $15 \mathrm{mg}$ of CBD caused alertness and counteracted the residual sedative effect of THC. ${ }^{20}$ Another study showed that anandamide induced sleep and also increased the level of adenosine (sleep inducing substance) in the basal forebrain and these effects were blocked by rimonabant. The role of FAAH inhibitors which lack the addictive properties like psychotropic cannabinoids has also been seen. ${ }^{20}$
As psychoactive cannabinoid ligands may not be desirable for use in insomnia, hence use of active FAAH inhibitors can be further evaluated for therapeutic gain as they lack addictive action.

\section{Pain}

Preclinical studies demonstrating the analgesic property of cannabinoids against chemical, mechanical and thermal pain stimuli are available. ${ }^{20,44}$ There is considerable evidence suggesting that cannabinoid signaling system functions parallely but distinctly from the opioids and their activation leads to antinociception along with other similar behavioural effects. ${ }^{42}$ In experimental animals with neuropathic pain, activation of opioid and cannabinoid receptors by their respective agonists leads to antinociceptive action. ${ }^{14}$ Data from studies on intact animal models show that acute administration of THC or other $\mathrm{CB}$ receptor agonists led to opioid peptide release while chronic administration of THC increased the gene expression of endogenous opioid precursors (preproenkephalin, prodynorphin and proopiomelanocortin). $^{45}$

Human studies with cannabinoids have shown mixed results. A buccal spray, Sativex (CBD +THC) was found to be effective in management of neuropathic pain in patients suffering from traumatic nerve injury or multiple sclerosis. ${ }^{46}$ Dronabinol has also been reported to provide relief from pain in patients with multiple sclerosis. ${ }^{47}$ In contrast, in a clinal study, Sativex did not provide any relief from central neuropathic pain due to brachial plexus avulsion. Dronabinol did not show analgesic effect in neuropathic pain and post-operative pain in a clinical trial. ${ }^{20} \mathrm{~A}$ clinical study with a synthetically modified compound derived from THC metabolite, THC-11-oic acid (ajulemic acid) has shown antinociceptive activity without causing neurological side effects of cannabinoids. The mechanism of action here might involve inhibition of cyclooxygenase-2 as ajulemic acid does not bind strongly to cannabinoid receptors. ${ }^{14}$

Currently there is not sufficient evidence in humans regarding the analgesic potential of cannabinoids and the mechanism of action also remains unclear. But animal data have predicted that cannabinoids have antinociceptive activity and it therefore needs to be further determined in future human studies and a better understanding of the underlying mechanism would also be useful.

\section{Cardiovascular diseases}

The most consistent effects of marijuana smoking and intravenous administration of THC are peripheral vasodilation and tachycardia. ${ }^{14} \mathrm{CB}_{1}$ receptors are more important in cardiovascular regulation while $\mathrm{CB}_{2}$ receptors are involved in ischemic preconditioning and ischemia/reperfusion injury of the myocardium. ${ }^{20} \mathrm{CB}_{1}$ receptors have been detected in human, rat and mouse 
myocardium where they have a negative inotropic effect and in vascular tissues where they cause vasodilation. These effects lead to hypotensive action of anandamide seen in anaesthetized rodents. ${ }^{20,48,49,50}$ In anaesthetized spontaneously hypertensive rats (SHR), THC and anandamide caused a long lasting hypotension than in control group and administration of $\mathrm{CB}_{1}$ receptor antagonists markedly increase the blood pressure and cardiac contractility further. ${ }^{20,48,51}$

A clinical study in male cannabis smokers, reported that $22 \%$ of them experienced symptomatic hypotension which could be attenuated by giving $30-90 \mathrm{mg}$ of rimonabant indicating that $\mathrm{CB}_{1}$ receptors mediate the hypotensive effect. ${ }^{52}$. These findings suggested the effect of endocannabinoids in hypertension is primarily mediated by tonic activation of cardiac and vascular $\mathrm{CB}_{1}$ receptors which are upregulated or due to increase in its signaling system. ${ }^{48}$

In myocardial reperfusion injury, role of $\mathrm{CB}_{2}$ receptors has been implicated and synthetic $\mathrm{CB}_{2}$ receptor agonists by action on endothelial cells from human coronary artery disease reduced the activation by TNF- $\alpha$ and production of other chemokines. ${ }^{53}$ In anesthetized rats, where ischemia/reperfusion injury was induced by coronary occlusion/ reocclusion, anandamide decreased both the incidence of ventricular arrhythmias and infarct size by activation of $\mathrm{CB}_{2}$ receptors and not $\mathrm{CB}_{1}$ receptors. $\mathrm{A}$ moderately selective $C_{2}$ receptor agonist reduced the myocardial damage in an animal model of ischemia/reperfusion which was abolished by selective $\mathrm{CB}_{2}$ receptor antagonist, indicating that the protective effect of endocannabinoids against myocardial ischemic injury mainly occurs via $\mathrm{CB}_{2}$ receptors. ${ }^{20,54}$

Another role postulated for endocannabinoids is their effect on progression of atherosclerosis. Cannabinoids exert potent anti inflammatory and antioxidant effects. Stimulation of $\mathrm{CB}_{2}$ receptors leads to decrease in the inflammatory activity of $\mathrm{TNF}-\alpha$, generation of high glucose induced mitochondrial superoxide, NF-kappa B activation and other inflammatory mediators and this can be helpful in atherosclerosis. ${ }^{55}$

Hence the role of cannabinoid receptors suggested in the treatment of cardiovascular disease seems beneficial. They appear to be a useful therapeutic target as $\mathrm{CB}_{1}$ receptors have shown promise in hypertension and $\mathrm{CB}_{2}$ receptors play an important role in myocardial perfusion injury and atherosclerosis by their anti-inflammatory and anti oxidant effects.

\section{Cancer}

The palliative effects of cannabinoids in cancer patients include appetite stimulation, inhibition of chemotherapy/ radiotherapy induced nausea and vomiting, analgesia, mood elevation and relief from insomnia. Many other potential benefits of cannabinoids have been and are still being evaluated in various tumors and the proposed mechanisms by which they show anti tumor action are anti proliferative action, inhibition of angiogenesis and tumor cell migration. ${ }^{20}$ The anti-tumor action of cannabinoids on glioma may be exerted either via $\mathrm{CB}_{1}$ or $\mathrm{CB}_{2}$ receptors. Intratumour administration of $\mathrm{THC}$ and $\mathrm{CB}_{1}$ agonist induced regression of glioma in wistar rats and in RAG-2-deficient mice. ${ }^{56}$ Selective $\mathrm{CB}_{2}$ receptor agonists showed good efficacy in vivo by regressing human astrocytoma Grade IV. ${ }^{57}$ Cannabinoid receptors could have a protective role against programmed cell death, as reported in human neuroblastoma and C6 cells, where AEA induced apoptosis by action on vanilloid receptors, activation of $\mathrm{COX}$, increase in intracellular calcium concentration, release of cytochrome $\mathrm{c}$ and activation of caspase $3 .^{58}$ Therefore the mechanism of AEA induced apoptosis in cells expressing both cannabinoid and vanilloid receptors is still controversial and might depend on the experiment conducted.

Studies investigating the role of AEA in breast tumor cells showed that, submicromolar concentration of AEA caused inhibition of mitogen induced activation of G0/G1-S phase in epithelial human breast cell lines (HBCC) EFM-19 and MCF-7 ${ }^{59}$, while HBCC lines MCF-7 and MDA-MB-231, mouse breast cancer 4T1 were found to be resistant to the cytotoxic action of THC and caused tumor proliferation. ${ }^{60}$ The difference in the response could be attributed to the level of cannabinoid receptor expression where low density of receptors could result in tumor progression on exposure to THC. ${ }^{61}$ Also it was said that $4 \mathrm{~T} 1$ cells expressed a good number of vanilloid receptors which is a target for AEA and hence these cells may be more responsive to action by AEA rather than THC. $^{62}$ In colorectal cancer, apoptotic and antiproliferative effects are mediated by $\mathrm{CB}_{1}$ receptors and AEA inhibited migration of cancer cells and cell death in apoptosis resistant cancer cells via $\mathrm{CB}_{1}$, depending on the presence of cyclo-oxygenase 2, which is abundantly expressed in colon tumor cells. ${ }^{63}$ Role of FAAH in colon tumor by increasing endocannabinoid levels has also been postulated and both these targets maybe helpful in clinical management of colorectal carcinoma.

Cannabinoids also have a role in other cancers like androgen dependent prostate cancer (apoptosis of human prostate cancer cells by G1 arrest) and pancreatic cancer (apoptosis of cancer cells via stress protein $\mathrm{p} 8$ and other genes). ${ }^{64,65}$

The difference in activity of cannabinoids in different tumor models can be attributed to the variability in expression of $\mathrm{CB}_{1}$ and $\mathrm{CB}_{2}$ receptors. Tumors like glioma and human astrocytoma grade IV have shown good response while in breast cancer cell lines, low density of cannabinoid receptors resulted in proliferation of tumor on exposure to THC. The battle is not lost yet, as many of the findings are encouraging and propose the beneficial role of cannabinoids in inhibiting tumor proliferation. 
Still a lot of extensive studies are warranted which can give a clear picture of the 'good' and the 'bad' effects of cannabinoids on different tumors and it needs to be seen if the same can be translated to clinical practice.

\section{Liver diseases}

The hepatic endocannabinoid system comprises of both $\mathrm{CB}_{1}$ and $\mathrm{CB}_{2}$ receptors which have a faint distribution, where $\mathrm{CB}_{1}$ receptors are present in endothelial cells and hepatocytes while $\mathrm{CB}_{2}$ receptors are distributed in Kupffer cells. Any liver injury leads to increase in the hepato endocannabinoid tone. ${ }^{66}$

The role of $\mathrm{CB}_{1}$ receptors in non-alcoholic fatty liver disease (NAFLD) was investigated in some experimental animals and the data showed that there occurred marked induction of $\mathrm{CB}_{1}$ receptors in NAFLD which promoted obesity leading to fatty liver and insulin resistance. Therefore selectively targeting $\mathrm{CB}_{1}$ receptors with agents lacking brain penetrance may prove to be an effective treatment option in such patients. ${ }^{67,68}$ The role of $\mathrm{CB}_{2}$ receptors on adipose tissue inflammation was also evaluated. It was seen that treatment with $\mathrm{CB}_{2}$ selective agonist in obese mouse model, led to increase in insulin resistance and liver steatogenesis associated with obesity. ${ }^{69}$

Cannabinoids are also said to be involved in the pathogenesis of alcoholic liver disease. Rimonabant by antagonizing $\mathrm{CB}_{1}$ receptors prevented the development of fatty liver in mice fed with an ethanol diet. This was because of paracrine activation of $\mathrm{CB}_{1}$ receptors in surrounding liver cells and activation of lipogenesis along with inhibition of fatty acid oxidation. ${ }^{70}$

Patients with chronic liver diseases may eventually develop liver cirrhosis, portal hypertension and liver failure. Search for effective liver specific anti fibrotic treatments is still continuing and the role of cannabinoid receptors has been explored for this. $\mathrm{CB}_{2}$ receptors show antifibrogenic properties as administration of its agonist in cirrhotic rats showed an improvement in liver fibrosis, decrease in the inflammation and increased apoptosis of hepatic myofibroblasts. ${ }^{70,71}$ As $\mathrm{CB}_{1}$ receptors are profibrogenic, so treatment with rimonabant or in $\mathrm{CB}_{1}$ knock-out mice, reduction in TGF- $\beta 1$ (profibrogenic) and fibrogenic cell levels were seen. It therefore, seems likely that selective $C_{2}$ receptor agonists and peripherally restricted $\mathrm{CB}_{1}$ receptor antagonists could provide a breakthrough in management of liver fibrosis.

As outlined above, growing evidences suggest that endocannabinoids are involved in various pathophysiological processes of liver diseases like NAFLD, alcoholic liver disease, chronic liver disease and its complications. $\mathrm{CB}_{1}$ receptors have an important role in NAFLD and alcoholic liver disease while the antiinflammatory action CB2 receptors can be useful in liver inflammatory conditions. As of now, more preclinical studies are required to accurately delineate the conditions where we can make use of agonists/ antagonists of CB receptors and then proceed to clinical studies to further substantiate their beneficial effects in these potential therapeutic indications.

\section{Gastrointestinal diseases}

Historically, marijuana was prescribed for the treatment of diarrhea and inflammatory bowel disease. ${ }^{72}$ But recent evidences indicate that cannabinoids can be used for a variety of gastrointestinal diseases like nausea and vomiting, gastric ulcers, irritable bowel syndrome, inflammatory bowel diseases and gastrointestinal reflux disease. $^{14,73,74,75}$

\section{Gastrointestinal reflux disease (GERD)}

$\Delta^{9}$ - tetrahydrocannabinol has been shown to decrease meal induced transient lower esophageal sphincter relaxation and lower esophageal sphincter pressure in humans. $^{76}$

\section{Irritable Bowel Syndrome (IBS)}

Cannabinoids are the major relaxants of gastrointestinal motility and $\mathrm{CB}_{1}$ controls peristalsis. ${ }^{77}$ Pharmacological studies have demonstrated that anandamide and various $\mathrm{CB}_{1}$ agonists inhibit gastrointestinal motility in rodens in vivo and in isolated ileum and colon from both animals and humans. ${ }^{20,80,81}$ In clinical trials with rimonabant for nicotine cessation or obesity, it was seen that incidence of diarrhea was higher in patients receiving rimonabant than with placebo. Therefore this suggests that blocking $\mathrm{CB}_{1}$ receptors accelerated gastrointestinal transit and secretions $^{20}$, so $\mathrm{CB}_{1}$ agonists may prove useful in diarrhea-predominant IBS while $\mathrm{CB}_{1}$ antagonists can help in constipation- predominant IBS. ${ }^{80}$

\section{Inflammatory Bowel Disease (IBD)}

It comprises of two clinical manifestations, Crohn's disease and ulcerative colitis and is associated with uncontrolled immune response to microbial antigens. $\mathrm{CB}_{1}$ receptors were seen to be involved in compensatory protective mechanisms in mice with chemically (croton oil, 2,4-dinitro benzene sulfonic acid and dextran sulfate) induced colitis. There occurs up regulation of $\mathrm{CB}_{1}$ receptors and $\mathrm{CB}_{1}$ agonists inhibited intestinal motility in these mice as compared to controls. ${ }^{72,81}$ In contrast, role of endocannabinoids in pathophysiology of complicated diverticulitis, a frequent complication of colitis, was also suggested as anandamide levels were raised and there was desensitization of presynaptic neural $\mathrm{CB}_{1}$ receptors in colonic longitudinal muscle strips from patients undergoing surgery for this complication. ${ }^{82}$

\section{Gastric ulcer}

In isolated stomach preparations, inhibition of histamine induced gastric and intestinal secretion by THC was demonstrated. ${ }^{20}$ Also $\mathrm{CB}_{1}$ agonists inhibited pentagastrin induced gastric acid secretion and this action could be prevented by $\mathrm{CB}_{1}$ antagonist. ${ }^{83,84}$ Anti ulcer activity of 
$\mathrm{CB}_{1}$ agonists was demonstrated in rat model of aspirin and cold resistant stress induced gastric ulcers. ${ }^{20}$

Cannabinoids offers a novel opportunity for future drug targeting by either cannabinoid receptor modulation via specific agonists/ antagonists or inhibition of FAAH and its transporters which increase the cannabinoid levels. Agonists of $\mathrm{CB}_{1}$ receptors can be useful in diarrhea predominant IBS, IBD, gastric ulcers while $\mathrm{CB}_{2}$ agonists have an important role in constipation predominant IBS. $\mathrm{CB}_{1}$ receptors are predominantly present in brain, hence its ligands may be associated with neurological side effects which may be a cause of concern. The need is to introduce more peripherally acting $\mathrm{CB}_{1}$ ligands with limited brain penetration or explore $\mathrm{CB}_{2}$ receptors more as they have low expression in the brain. Developing agents that are more efficacious and lacking the psychoactive side effects would be a better treatment option.

\section{Dermatological diseases}

Cutaneous endocannabinoid system (ECS) has been shown to be important in the regulation of skin cell proliferation, survival and differentiation which regulates cutaneous homeostasis. By proper modulation of ECS in the skin, various skin diseases may find a new therapeutic target for action. Hyperproliferative skin diseases like psoriasis in which there occurs increased turnover of epidermal keratinocyte proliferation and skin cancers can benefit from the fact that ECS inhibits cell growth, angiogenesis and induces apoptosis in many types of skin cells. Cannabinoid receptor 1 agonism can be used in hirsuitism as $\mathrm{CB}_{1}$ receptor negatively regulates hair growth while by antagonizing $\mathrm{CB}_{1}$ receptor, conditions like alopecia areata may be treated. ${ }^{85}$

In sebaceous glands, $\mathrm{CB}_{2}$ receptor activation can increase lipid synthesis. Antagonizing these receptors in diseased sebaceous glands conditions (acne, seborrhea), can be a new promising drug target ${ }^{85}$ while sebaceous gland $\mathrm{CB}_{2}$ receptor agonists can be exploited in dry skin diseases and itching. Topical formulations containing cannabinoids which enhance ECS tone in skin can be of use in skin inflammations and a recent study has stated about the use of $\mathrm{CB}_{2}$ receptor agonists for management of early inflammatory stages of systemic sclerosis. ${ }^{86}$

The above data suggests an important role of cutaneous ECS in normal physiological processes of skin and focus should be on proper targeting of the cannabinoid system in various pathological skin diseases. The studies available till now have shown positive results but still, there is a long way to go and the in depth knowledge and exploration of the complete potential of cutaneous ECS requires further evaluation.

\section{Asthma}

Marijuana smoking and ingestion of THC caused an increase in the airway conductance in normal healthy subjects and, in subjects with mild to moderate asthma, it caused a relief in bronchospasm. ${ }^{20}$ In animal studies, rimonabant enhanced capsaicin induced bronchospasm and cough in guinea pig while anandamide inhibited this effect of rimonabant suggesting the presence of $\mathrm{CB}_{1}$ receptors on axon terminals innervating airway smooth muscles. ${ }^{20} \mathrm{~A}$ recent study of capsaicin induced cough in mice showed that inhibition of anandamide transporter suppressed cough and this may be a new target for cough management. ${ }^{87}$ Role of cannabinoids in allergic asthma due to its anti inflammatory effect of decreasing serum IgE levels, interleukin expression and mucous overproduction can be of medicinal potential. ${ }^{20,88}$

The effects of cannabinoids on respiratory system are complex and psychoactive effects can limit the use of $\mathrm{CB}_{1}$ receptor ligands, therefore non psychoactive cannabinoid compounds can be a good therapeutic option and targeting cannabinoids for their anti inflammatory property in allergic asthma seems effective.

\section{Eye diseases}

\section{Glaucoma and Diabetic retinopathy}

In healthy marijuana smokers, a decrease in intra ocular pressure (IOP) was an accidental finding which was then confirmed in various studies where natural marijuana with THC or synthetic THC (orally, topically or intravenously) showed a decrease in IOP. The side effects reported were hypotension, tachycardia, euphoria, changes in pupil size, decreased tear production and conjunctival hyperemia. ${ }^{20}$ Also in animal studies, topical administration of AEA caused a significant decrease in intra ocular pressure (IOP) in normotensive albino and pigmented rabbits. ${ }^{89}$ Evidence available suggest the role of $\mathrm{CB}_{1}$ receptors in regulation of IOP as they are present in rat ciliary body, human ciliary epithelium, ciliary muscle, ciliary body vessels, trabecular meshwork, Schlemm's canal and retina. ${ }^{20,90,91}$ Topical application of $\mathrm{CB}_{1}$ receptor agonists in animals as well as humans reduced IOP and $\mathrm{CB}_{2}$ receptor agonist did not effect IOP suggesting that IOP regulation is not majorly effected by $\mathrm{CB}_{2}$ receptors. ${ }^{92,93}$ Mechanisms by which cannabinoids lower IOP is still not clear but they may have an effect on ciliary processes by causing vasodilatation, reduction of capillary pressure and secretion. They can also cause a decrease in aqueous humor production by inhibiting calcium influx in presynaptic ion channels thus decreasing the release of norepinephrine in ciliary body and may improve uveoscleral outflow by dilatation of anterior uveal vessels. $^{20}$ All these factors further substantiate the beneficial role of cannabinoids in glaucoma and required is a preparation which can acting locally and have least side effects.

The antioxidative and anti-inflammatory effect of cannabinoids represents a novel therapeutic approach for the diabetic complications of the eye. Adenosine and its agonists have a protective role in inflammation in various animal models and cannabinoids have been shown to 
inhibit its reuptake in murine microglia by a non cannabinoid receptor mechanism, thus inhibiting diabetesinduced retinal inflammation. ${ }^{94}$ Therefore the neuroprotective role of cannabinoids in diabetic retinopathy seems to have a good potential and needs further evaluation.

\section{CONCLUSION}

Marijuana was used for centuries as a medicinal plant but during the last century, because of its addictive potential, it was taken out of clinical practice. The discovery of the endocannabinoid signaling system opened new possibilities for research into understanding the mechanism of action of cannabinoids and their therapeutic potential in various diseases. Cannabinoid receptor agonists/ antagonists have been found to be useful in management of plethora of diseases. Now we believe that cannabinoid and its constituents along with its related compounds need to be brought back into clinical use and the reasons are their medicinal potential as described in the present review. The therapeutic benefits of cannabinoids outweigh the negative aspects and the potential clinical use of such a system should not be neglected and instead a target oriented approach to study and characterize specific or more selective agonists/ antagonists with selective distribution patterns is the need of the hour, so that the desirable clinical effects are retained while the undesirable effects are minimized.

\section{REFERENCES}

1. Hiley CR. Endocannabinoids and the Heart. J Cardiovasc Pharmacol 2009;53(4):267-76.

2. Rang HP, Dale MM, Ritter JM, Flower RJ. Cannabinoids. In: Rang HP, Dale MM, Ritter JM, Flower RJ, eds. Rang and Dale's Pharmacology $6^{\text {th }}$ edition. Philadelphia: Churchill Livingstone Elsevier; 2007:248-55.

3. Howlett AC, Barth F, Bonner TI, Cabral G, Casellas $\mathrm{P}$, Devane WA et al. International Union of Pharmacology. XXVII. Classification of cannabinoid receptors. Pharmaco Rev 2002;54:161202.

4. De Petrocellis L, Cascio MG, Di Marzo V. The endocannabinoid system: a general view and latest additions. Br J Pharmacol 2004;141:765-74.

5. O'Sullivan S. Cannabinoids go nuclear: evidence for activation of peroxisome proliferator-activated receptors. Br J Pharmacol 2007;152:576-82.

6. Van Sickle MD, Duncan M, Kingsley PJ, Mouihate A, Urbani P, Mackie $\mathrm{K}$ et al. Identification and functional characterization of brainstem cannabinoid $\mathrm{CB}_{2}$ receptors. Science 2005;310:329-32.

7. Seely KA, Prather PL, James LP, Moran JH. Marijuana based drugs: Innovative therapeutics or designer drugs of Abuse? Mol Interv 2011;11(1):3651.

8. Pacher P, Batkai $\mathrm{S}$ and Kunos G. The Endocannabinoid System as an Emerging Target of
Pharmacotherapy. Pharmacol Rev 2006;58(3):389462.

9. Gonsiorek W, Lunn C, Fan X, Narula S, Lundell D, Hipkin RW. Endocannabinoid 2-arachidonyl glycerol is a full agonist through human type 2 cannabinoid receptor: antagonism by anandamide. Mol Pharmacol 2000;57:1045-50.

10. Goparaju SK, Ueda N, Yamaguchi H, Yamamoto S. Anandamide amidohydrolase reacting with 2arachidonoylglycerol, another cannabinoid receptor ligand. FEBS Lett 1998;422:69-73.

11. Dinh TP, Carpenter D, Leslie FM, Freund TF, Katona I, Sensi SL, Kathuria S, Piomelli D. Brain monoglyceride lipase participating in endocannabinoid inactivation. Proc Natl Acad Sci USA 2002;99:10819-24.

12. Dinh TP, Freund TF, Piomelli D. A role for monoglyceride lipase in 2-arachidonoylglycerol inactivation. Chem Phys Lipids 2002;121:49.

13. Witkamp RF. Current and future drug targets in weight management. Pharm Res 2011;28:1792-818.

14. Grant I, Cahn BR. Cannabis and endocannabinoid modulators: Therapeutic promises and challenges. Clin Neurosci Res 2005;5(2-4):185-99.

15. Kogan NM, Mechoulam R. Cannabinoids in health and disease. Dialogues Clin Neurosci 2007;9:41330.

16. Tramer MR, Campbell FA, Reynolds JM, Moore RA, McQuay HJ. Cannabinoids for control of chemotherapy induced nausea and vomiting: quantitative systematic review. BMJ 2001;323:1621.

17. Cluny NL, Vemuri VK, Chambers AP, Limebeer CL, Bedard H, Wood JT et al. A novel peripherally restricted cannabinoid receptor antagonist, AM6545, reduces food intake and body weight, but does not cause malaise, in rodents. $\mathrm{Br} \mathrm{J}$ Pharmacol 2010;161:629-42.

18. Witkamp RF. Current and future drug targets in weight management. Pharm Res 2011;28:1792-818.

19. Cabral GA and Thomas LG. Cannabinoids as therapeutic agents for ablating neuroinflammatory disease. Endocr Metab Immune Disord Drug Targets 2008;8(3):159-72.

20. Pacher P, Batkai S, Kunos G. The Endocannabinoid System as an Emerging Target of Pharmacotherapy. Pharmacol Rev 2006;58(3):389-462.

21. Benito C, Romero JP, Tolon RM, Clemente D, Docagne F, Hillard CJ et al. Cannabinoid CB1 and CB2 Receptors and Fatty Acid Amide Hydrolase Are Specific Markers of Plaque Cell Subtypes in Human Multiple Sclerosis. J Neurosci 2007;27(9):2396-402.

22. Scotter EL, Abood ME, Glass M. The endocannabinoid system as a target for the treatment of neurodegenerative disease. $\mathrm{Br} \mathrm{J}$ Pharmacol 2010;160:480-98.

23. Sheng WS, Hu S, Min X, Cabral GA, Lokensgard JR, Peterson PK. Synthetic cannabinoid WIN55, 212-212 inhibits generation of inflammatory 
mediators by IL-1 $\beta$-stimulated human astrocytes. Glia 2005;49:211-9.

24. Baker D, Pryce G, Croxford JL, Brown P, Pertwee RG, Makriyannis A et al. Endocannabinoids control spasticity in a multiple sclerosis model. FASEB J 2001;15(2):300-2.

25. Ligresti A, Cascio MG, Pryce G, Kulasegram S, Beletskaya I, Petrocellis LD. New potent and selective inhibitors of anandamide reuptake with antispastic activity in a mouse model of multiple sclerosis. Br J Pharmacol 2006;147:83-91.

26. Nagarkatti P, Pandey R, Rieder SA, Hegde VL, Nagarkatti M. Cannabinoids as novel antiinflammatory drugs. Future Med Chem 2009;1(7):1333-49.

27. Zajicek JP, Wright DE, Vickery PJ, Ingram WM, Reilly SM et al. Cannabinoids in multiple sclerosis (CAMS) study: safety and efficacy data for 12 months follow up. J Neurol Neurosurg Psychiatry 2005;76:1664-9.

28. Greenberg HS, Werness SA, Pugh JE, Andrus RO, Anderson DJ, Domino EF. Short-term effects of smoking marijuana on balance in patients with multiple sclerosis and normal volunteers. Clin Pharmacol Ther 1994;55(3):324-8.

29. Gerdeman G, Lovinger DM. CB1 Cannabinoid Receptor Inhibits Synaptic Release of Glutamate in Rat Dorsolateral Striatum. J Neurophysiol 2001;85:468-71.

30. Brotchie JM. CB1 cannabinoid receptor signaling in Parkinson's disease. Curr Opin Pharmacol 2003;3:54-61.

31. Eubanks LM, Rogers CJ, Beuscher AE, Koob GF, Olson AJ, Dickerson TJ et al. A molecular link between the active component of marijuana and Alzheimer's disease pathology. Mol Pharm 2006;3:773-7.

32. Ehrhart J, Obregon D, Mori T, Hou H, Sun N, Bai Y et al. Stimulation of cannabinoid receptor $2\left(\mathrm{CB}_{2}\right)$ suppresses microglial activation. J Neuroinflammation 2005;2:29.

33. Sharma HL, Sharma KK. Antipsychotic drugs. In: Sharma HL, Sharma KK, eds. Principles of Pharmacology $2^{\text {nd }}$ edition. Hyderabad: Paras Medical Publisher; 2011:451-60.

34. Ujike H, Morita Y. New perspectives in the studies on endocannabinoid and cannabis: cannabinoid receptors and schizophrenia. J Pharmacol Sci 2004;96:376-81.

35. Turner WM, Tsuang MT. Impact of Substance Abuse on the Course and Outcome of Schizophrenia. Schizophr Bull 1990;16(1):87-95.

36. Johns A. Psychiatric effects of cannabis. $\mathrm{Br} \mathrm{J}$ Pharmacol 2001;178:116-22.

37. D'Souza DC, Perry E, MacDougall L, Ammerman Y, Cooper T, Wu Y et al. The Psychotomimetic Effects of Intravenous Delta-9Tetrahydrocannabinol in Healthy Individuals: Implications for Psychosis. Neuropharmacology 2004;29:1558-72.
38. Basu D, Malhotra A, Varma VK.Cannabis related psychiatric syndromes: A selective review. Indian J Psychiat 1994;36(3):121-8.

39. Giuffrida A, Leweke FM, Gerth CW, Schreiber D, Koethe D, Faulhaber $\mathrm{J}$ et al. Cerebrospinal Anandamide Levels are Elevated in Acute Schizophrenia and are Inversely Correlated with Psychotic symptoms. Neuropharmacology 2004;29:2108-14.

40. De Marchi N, De Petrocellis L, Orlando P, Daniele F, Fezza F, Di Marzo V. Endocannabinoid signalling in the blood of patients with schizophrenia. Lipids Health Dis 2003;2:5.

41. Marco EM, Gutierrez MSG, Silva FJB, Moreira FA, Guimaraes F, Manzanares J. Endocannabinoid system and psychiatry: in search of a neurobiological basis for detrimental and potential therapeutic effects. Front Behav Neurosci 2011;5:63.

42. Haller J, Bakos N, Szirmay M, Ledent C, Freund TF. The effects of genetic and pharmacological blockade of the CB1 cannabinoid receptor on anxiety. Eur J Neurosci 2002;16(7):1395.

43. Gaal LV, Sunyer XP, Despres JP, McCarthy C, Scheen A. Efficacy and Safety of Rimonabant for Improvement of Multiple Cardiometabolic Risk Factors in Overweight/Obese Patients. Pooled 1-year data from the Rimonabant in Obesity (RIO) program. Diabetes Care 2008;31 Suppl 2:S229-40.

44. Martin WJ, Hohmann AG, Walker JM. Suppression of Noxious Stimulus-Evoked Activity in the Ventral Posterolateral Nucleus of the Thalamus by a Cannabinoid Agonist: Correlation between Electrophysiological and Antinociceptive Effects. J Neurosci 1996;16(20):6601-11.

45. Bushlin I, Rozenfeld R and Devi LA. Cannabinoidopioid interactions during neuropathic pain and analgesia. Curr Opin Pharmacol 2010;10(1):80-6.

46. Iskedjian $\mathrm{M}$, Bereza $\mathrm{B}$, Gordon $\mathrm{A}$, Piwko C, Einarson TR. Meta-analysis of cannabis based treatments for neuropathic and multiple sclerosisrelated pain. Curr Med Res Opin 2007;23:17-24.

47. Svendsen KB, Jensen TS, Bach FW. Does the cannabinoid dronabinol reduce central pain in multiple sclerosis? Randomised double blind placebo controlled crossover trial. BMJ 2004;329(7460):253.

48. Batkai S, Pacher P, Hyiaman DO, Radaeva S, Liu J, White JH. Endocannabinoids Acting at Cannabinoid-1 Receptors Regulate Cardiovascular Function in Hypertension. Circulation 2004;110(14):1996-2002.

49. Liu J, Gao B, Mirshahi F, Sanyal AJ, Khanolkar AD, Makriyannis A. Functional CB1 cannabinoid receptors in human vascular endothelial cells. Biochem J 2000;346:835-40.

50. Gebremedhin D, Lange AR, Campbell WB, Hillard CJ, Harder DR. Cannabinoid CB1 receptor of cat cerebral arterial muscle functions to inhibit L-type Ca2+ channel current. Am J Physiol 1999;276(6 Pt 2):H2085-93. 
51. Lake KD, Martin BR, Kunos G, Varga K. Cardiovascular Effects of Anandamide in Anesthetized and Conscious Normotensive and Hypertensive Rats. Hypertension 1997;29:1204-10.

52. Gorelick DA, Heishman SJ, Preston KL, Nelson RA, Moolchan ET, Huestis MA. The cannabinoid CB1 receptor antagonist rimonabant attenuates the hypotensive effect of smoked marijuana in male smokers. Am Heart J 2006;151(3):754.e1-754.e5.

53. Rajesh M, Mukhopadhyay P, Bátkai S, Haskó G, Liaudet L, Huffman JW, Csiszar A, Ungvari Z, Mackie K, Chatterjee S, Pacher P. CB2-receptor stimulation attenuates TNF-a-induced human endothelial cell activation, transendothelial migration of monocytes, and monocyte-endothelial adhesion. Am J Physiol 2007;293:H2210-8.

54. Filippo CD, Rossi F, Rossi S, D’Amico M. Cannabinoid CB2 receptor activation reduces mouse myocardial ischemia-reperfusion injury: involvement of cytokine/chemokines and PMN. J Leukoc Biol 2004;75:453-9.

55. Rajesh M, Mukhopadhyay P, Batkai S, Hasko G, Liaudet L, Drel VR et al. Cannabidiol attenuates high glucose-induced endothelial cell inflammatory response and barrier disruption. Am J Physiol Heart Circ Physiol 2007;293(1):H610-9.

56. Bifulco M, Laezza C, Pisanti S, Gazzerro P. Cannabinoids and cancer: pros and cons of an antitumor strategy. Br J Pharmacol 2006;148:12335.

57. Sanchez C, de Ceballos ML, del Pulgar TG, Rueda D,Corbacho C, Velasco G, Galve-roperh I, Huffman JW, Ramon YCS and Guzman M. Inhibition of glioma growth in vivo by selective activation of the $\mathrm{cb}(2)$ cannabinoid receptor. Cancer Res 2001;61:5784-9.

58. Maccarrone M, Lorenzon T, Bari M, Melino G, Finazzi-Agro A. Anandamide induces apoptosis in human cells via vanilloid receptors. Evidence for a protective role of cannabinoid receptors. J Biol Chem 2000;275(41):31938-45.

59. De Petrocellis L, Melck D, Palmisano A, Bisogno T, Laezza C, Bifulco $\mathrm{M}$ and Dimarzo V. The endogenous cannabinoid anandamide inhibits human breast cancer cell proliferation. Proc Natl Acad Sci U.S.A 1998;95:8375-80.

60. Mckallip RJ, Nagarkatti $M$ and Nagarkatti PS. Delta-9-tetrahydrocannabinol enhances breast cancer growth and metastasis by suppression of the antitumor immune response. J Immunol 2005;174:3281-9.

61. Hamelers IHL, Vanschaik RFMA, Sussenback JS and Steenbergh PH. 17b-Estradiol responsiveness of MCF-7 laboratory strains is dependent on an autocrine signal activating the IGF type I receptor. Cancer Cell Int 2003;3:10-20.

62. Melck D, De petrocellis L, Orlando P, Bisogno T, Laezza C, Bifulco M and Dima rzo V. Suppression of nerve growth factor Trk receptors and prolactin receptors by endocannabinoids leads to inhibition of human breast and prostate cancer cell proliferation. Endocrinology 2000;141:118-26.

63. Patsos HA, Hicks DJ, Dobson RR, Greenhough A, Woodman N, Lane JD et al. The endogenous cannabinoid, anandamide, induces cell death in colorectal carcinoma cells: A possible role for cyclooxygenase 2 . Gut 2005;54:1741-50.

64. Carracedo A, Gironella M, Lorente M, Garcia S, Guzman M, Velasco $\mathrm{M}$ et al. Cannabinoids induce apoptosis of pancreatic tumor cells via endoplasmic reticulum stress-related genes. Cancer Res 2006;66:6748-55.

65. Sarfaraz S, Afaq F, Adhami VM, Malik A, Mukhtar H. Cannabinoid receptor agonist-induced apoptosis of human prostate cancer cells LNCaP proceeds through sustained activation of ERK1/2 leading to G1 cell cycle arrest. J Biol Chem 2006;281:3948091.

66. Mallat A, Lotersztajn S. Endocannabinoids and Their Receptors in the Liver. Am J Physiol Gastrointest Liver Physiol 2008;294:G9-G12.

67. Cluny NL, Vemuri VK, Chambers AP, Limebeer CL, Bedard H, Wood JT et al. A novel peripherally restricted cannabinoid receptor antagonist, AM6545, reduces food intake and body weight, but does not cause malaise, in rodents. $\mathrm{Br} \mathrm{J}$ Pharmacol 2010;161:629-42.

68. Tam J, Vemuri VK, Liu J, Batkai S, Mukhopadhyay B, Godlewski G et al. Peripheral CB1 cannabinoid receptor blockade improves cardiometabolic risk in mouse models of obesity. J Clin Invest 2010;120:2953-66.

69. Mallat A, Clerc FT, Deveaux V, Manin S and Lotersztajn S. The endocannabinoid system as a key mediator during liver diseases: new insights and therapeutic openings. $\mathrm{Br} \quad \mathrm{J}$ Pharmacol 2011;163:1432-40.

70. Teixeira-Clerc F, Belot MP, Manin S, Deveaux V, Cadoudal T, Chobert MN et al. Beneficial paracrine effects of cannabinoid receptor 2 on liver injury and regeneration. J Hepatology 2010;52(3):1046-59.

71. Munoz-Luque J, Ros J, Fernandez-Varo G, Tugues S, Morales-Ruiz M, Alvarez CE et al. Regression of fibrosis after chronic stimulation of cannabinoid CB2 receptor in cirrhotic rats. J Pharmacol Exp Ther 2008;324:475-83.

72. Massa F, Marsicano G, Hermann H, Cannich A, Monory K, Cravatt BF et al. The endogenous cannabinoid system protects against colonic inflammation. J Clin Invest 2004;113:1202-9.

73. Kunos G, Pacher P. Cannabinoids cool the intestine. Nat Med 2004;10(7):678-9.

74. Pertwee RG. Cannabinoids and the gastrointestinal tract. Gut 2001;48:859-67.

75. Schicho R, Storr M. Alternative targets within the endocannabinoid system for future treatment of gastrointestinal diseases. Can J Gastroenterol 2011;25(7):377-83.

76. Beaumont $\mathrm{H}$, Jensen $\mathrm{J}$, Carlsson A, Ruth $\mathrm{M}$, Lehmann A, Boeckxstaens G. Effect of delta 9- 
tetrahydrocannabinol, a cannabinoid receptor agonist, on the triggering of transient lower oesophageal sphincter relaxations in dogs and humans. Br J Pharmacol 2009;156:153-62.

77. Grider JR, Mahavadi S, Li Y, Qiao LY, Kuemmerle JF, Murthy KS et al. Modulation of motor and sensory pathways of the peristaltic reflex by cannabinoids. Am J Physiol Gastrointest Liver Physiol 2009;297:G539-49.

78. Coutts AA, Pertwee RG. Inhibition by cannabinoid receptor agonists of acetylcholine release from the guinea-pig myenteric plexus. $\mathrm{Br} \mathrm{J}$ Pharmacol 1997;121:1557-66.

79. Hinds NM, Ullrich K, Smid SD. Cannabinoid 1 (CB1) receptors coupled to cholinergic motorneurones inhibit neurogenic circular muscle contractility in the human colon. Br J Pharmacol 2006;148:191-9.

80. Wang A, Liao X, Xiong L, Peng S, Xiao Y, Liu S et al. The clinical overlap between functional dyspepsia and irritable bowel syndrome based on Rome III criteria. BMC Gastroenterol 2008;8:43.

81. Izzo AA, Fezza F, Capasso R, Bisogno T, Pinto L, Luvone $\mathrm{T}$ et al. Cannabinoid CB1-receptor mediated regulation of gastrointestinal motility in mice in a model of intestinal inflammation. $\mathrm{Br} \mathrm{J}$ Pharmacol 2001;134:563-70.

82. Guagnini F, Valenti M, Mukenge S, Matias I, Bianchetti A, Palo SD et al. Neural contractions in colonic strips from patients with diverticular disease: role of endocannabinoids and substance P. Gut 2006;55:946-53.

83. Adami M, Frati P, Bertini S, Narla AK, Brown DR, De Caro $G$ et al. Gastric antisecretory role and immunohistochemical localization of cannabinoid receptors in the rat stomach. $\mathrm{Br} \mathrm{J}$ Pharmacol 2002;135:1598-606.

84. Coruzzi G, Adami M, Coppelli G, Frati P, Soldani G. Inhibitory effect of the cannabinoid receptor agonist WIN 55,212-2 on pentagastrin-induced gastric acid secretion in the anaesthetized rat. Naunyn Schmiedebergs Arch Pharmacol 1999;360(6):715-8.
85. Biro T, Toth BI, Hasko G, Paus R and Pal P. The endocannabinoid system of the skin in health and disease: novel perspectives and therapeutic opportunities. Trends Pharmacol 2009;30(8):411-20.

86. Akhmetshina A, et al. The cannabinoid receptor CB2 exerts antifibrotic effects in experimental dermal fibrosis. Arthritis Rheum 2009;60:1129-36.

87. Kamei J, Yoshikawa Y, Saitoh A. Effect of Narachidonoyl-(2-methyl-4-hydroxyphenyl) amine (VDM11), an anandamide transporter inhibitor, on capsaicin-induced cough in mice. Cough 2006;2:2.

88. Jan TR, Farraj AK, Harkema JR, Kaminski NE. Attenuation of the ovalbumin-induced allergic airway response by cannabinoid treatment in $\mathrm{A} / \mathrm{J}$ mice. Toxicol Appl Pharmacol 2003;188:24.

89. Pate DW, Jarvinen K, Urtti A, Jarho P, Jarvinen T. Ophthalmic arachidonylethanolamide decreases intraocular pressure in normotensive rabbits. Curr Eye Res 1995;14:791.

90. Straiker A, Stella N, Piomelli D, Mackie K, Karten HJ, Maguire G. Cannabinoid CB1 receptors and ligands in vertebrate retina: Localization and function of an endogenous signaling system. Proc Natl Acad Sci USA 1999;96(25):14565-70.

91. Straiker AJ, Maguire G, Mackie K, Lindsey J. Localization of cannabinoid CB1 receptors in the human anterior eye and retina. Investig Ophthalmol Vis Sci 1999;40:2442-8.

92. Song $\mathrm{ZH}$, Slowey CA. Involvement of cannabinoid receptors in the intraocular pressure-lowering effects of WIN55212-2. J Pharmacol Exp Ther 2000;292:136-9.

93. Chien FY, Wang RF, Mittag TW, Podos SM. Effect of WIN 55212-2, a cannabinoid receptor agonist, on aqueous humor dynamics in monkeys. Arch Ophthalmol 2003;121:87-90.

94. Liou GI,El-Remessy EB, Ibrahim AS, Caldwell RB, Khalifa YM, Gunes A et al. Cannabidiol As a Putative Novel Therapy for Diabetic Retinopathy: A Postulated Mechanism of Action as an Entry Point for Biomarker-Guided Clinical Development. Curr Pharmacogenomics Person Med 2009;7(3):215-22. 